\title{
Comparison of Penetration Performance and Penetration Mechanism of W-Cu Shaped Charge Liner against Three Kinds of Target: Pure Copper, Carbon Steel and Ti-6Al-4V alloy
}

\author{
Guo Wenqi $^{\text {a }}$, Liu Jinxu ${ }^{a, b, *}$,Xiao Yao ${ }^{a}$, Li Shukui ${ }^{a, b, c}$, Zhao Ziying ${ }^{a}$, Cao Jin ${ }^{a}$ \\ a School of Material Science and Engineering, Beijing Institute of Technology (BIT), No.5 \\ Zhongguancun South Street,Beijing, 100081, P.R. China \\ b Nationa Key Laboratory of Science and Technology on Materials under shock and impact, \\ Beijing, P.R. China \\ c State Key Laboratory of Explosion Science and Technology, Beijing, P.R. China. \\ *Corresponding author (Ph. D): E-mail: liujinxu@bit.edu.cn \\ Tel: +86-010-68913937-802, Fax: +86-010-68913937
}

\begin{abstract}
In order to investigate the interaction between shaped charge jet and target, three different targets, including pure copper target, carbon steel target and Ti-6Al-4V alloy target, were penetrated by $\mathrm{W}-\mathrm{Cu}$ shaped charge jet. Penetration performance and corresponding penetration mechanisms were studied. Calculated theoretical penetration depth ratio of Ti-6Al-4V alloy target, pure $\mathrm{Cu}$ target and carbon steel target is 10:2.8:5.7, while the practical penetration depth ratio is 10:28:21, indicating that the interaction between jet and target has a significant effect on the penetration depth. Microstructural analysis shows that the interaction between jet and $\mathrm{Cu}$ target is
\end{abstract}


the lightest among the three kinds of targets, leading to an increased penetration depth of $\mathrm{Cu}$ target. The interaction between jet and Ti-6Al-4V alloy target is the severest, resulting in an increased transverse energy dissipation of jet and decreased penetration depth of Ti-6Al-4V alloy target. Given the significant interaction between jet and target, we propose a modified equation of penetration depth by adding an empirical parameter, which provides a platform to predict more accurate penetration depth.

Key Words: Shaped Charge Liner, Target materials, Penetration Performance, Interaction, Microsructures

\section{Introduction}

Shaped charge liner (SCL) is the crucial unit of shaped charge warhead. Under explosive loading, the SCL materials are accelerated along the symmetry axis under cumulative effect [1-3]. The inwall of SCL forms a jet with extremely high tip velocity (as high as $10 \mathrm{~km} / \mathrm{s}$ ), which finally attacks the targets [4-5]. In many cases, penetration depth is considered the most important factor of penetration performance of SCL, thus extensive efforts have been made to improve the penetration depth of SCL. Pack and Evans [6] proposed an equation to describe the relationship between the penetration depth and the affecting factors.

$$
P=\left(\rho_{j} / \rho_{t}\right)^{1 / 2} L\left(1-\alpha \sigma_{t} / V^{2} \rho_{j}\right)
$$

$\rho_{j}$ and $\rho_{t}$ are the densities of the jet and the target, respectively. $L$ is the length of the jet, $V$ is the tip velocity of the jet, $\alpha$ is the empirical constant, and $\sigma_{t}$ is the strength of the target. According to equation (1), the density, length and velocity of the 
jet are three main factors influencing the penetration depth. Therefore, in order to obtain continuous jets with high density and high velocity, SCL materials should have good plasticity and high density. Pure metals such as $\mathrm{Cu}, \mathrm{Ni}$, Ta, Mo and $\mathrm{W}$ have been systematically investigated as SCL materials [7-10]. Preparation methods of these SCLs have been optimized and the corresponding penetration performances have been compared [11-13]. Some alloys and composites such as W-Cu alloy and Ni-W alloy also show good potential in the field of SCL [14-16]. However, all the above researches were focused on improving the penetration ability of the jet, underestimating or ignoring the effect of interaction between jet and target. Since the velocity of the jet is extremely high, the impact site during penetration process is under the condition of high pressure, high strain rate and high temperature. Since the penetration process is complicated, it is necessary to consider more than density and velocity of the jet. Bai Xi [17] compared the penetration properties of pure $\mathrm{W}$, W-Ni-Fe alloy and W-Cu alloy SCL against steel target. It was found that W-Cu SCL, with the lowest density and moderate tip velocity, exhibited the deepest penetration depth among the three SCLs. This indicates that the influence of target effect should also be regarded as an important factor to predict the performance of SCL.

In recent years, some researchers have also paid attention to the target effect on the penetration performance of shaped charge jet [18-19]. These work mainly discussed the effect of target structure on penetration performance of SCLs, but corresponding penetration mechanisms remains elusive. Oleg V. Svirsky [20] studied the jet penetration capability against finite thickness target, performing both 
numerical modeling and experiment of the interaction process between jet and finite-thickness target. But the results mainly focused on calculations with little further explanations. Z.X. Yin [21] studied the perforation surface and adiabatic shear bands in the matrix of ultra-high strength steel penetrated by shaped charge jet. Areas with different characteristics were found on the ballistic surface and phase transformation was discussed in details. However, the interaction between jet and target was not revealed and the corresponding penetration mechanism remains elusive.

In our previous work [17], ultra-hard phases of $\mathrm{Fe}_{0.95} \mathrm{~W}_{0.05}$ and martensite were found on the surface of targets penetrated by $\mathrm{W}$ and $\mathrm{W}-\mathrm{Ni}-\mathrm{Fe}$ SCLs. These ultra-hard phases hindered jets from penetrating the target further severely. While $\mathrm{Cu}$ in $\mathrm{W}-\mathrm{Cu}$ SCL did not form intermetallic with $\mathrm{W}$ or Fe, thus the penetration depth of W-Cu SCL is the highest. Zhao ziying [22] studied the penetration properties of $\mathrm{W}-\mathrm{Cu}, \mathrm{W}-\mathrm{Cu}-\mathrm{Ni}$ alloy and $\mathrm{W}-\mathrm{Cu}-\mathrm{Zn}$ alloy SCL against steel target. Results showed that the addition of $\mathrm{Ni}$ and $\mathrm{Zn}$ decreased the penetration depth. The affected zones in the targets penetrated by $\mathrm{W}-\mathrm{Cu}-\mathrm{Ni}$ alloy and $\mathrm{W}-\mathrm{Cu}-\mathrm{Zn}$ alloy SCL were enlarged, indicating a larger transverse dissipation of the jets. Above work prove that the interaction between jet and target is an important factor to influence the penetration performance of SCL, but some problems keep unsettled. First, the above two papers mainly compared different jets, with only one kind of target used. Different materials of shaped charge liners will result in different tip velocities of jets, which will change the penetration ability of jets. That means the interaction between jet and target were 
studied at variable conditions. In order to minimize the influence caused by different jets and obtain quantitative results, it is necessary to use one kind of SCL against different targets. Besides, the selected targets should have distinctive properties to acquire more obvious comparison. Active alloys such as titanium alloy target should be selected. At the same time, some non-active metals and alloys should also be selected for comparison. Studying the interaction between jet and target from the perspective of target will not only help to reveal different penetration mechanisms, but also help to develop the armor materials.

In the present work, three distinctive target materials including pure copper, carbon steel and Ti-6Al-4V alloy are designed as targets against penetration of $\mathrm{W}-\mathrm{Cu}$ shaped charge jet. W and $\mathrm{Cu}$ had distinctive properties, and neither solid solution nor chemical compound were formed in W-Cu alloy [14]. For pure copper target, neither solid solution nor chemical compound can be found in $\mathrm{W}-\mathrm{Cu}$ phase diagram, which indicates the interaction between $\mathrm{W}-\mathrm{Cu}$ jet and pure copper target may be slight. For carbon steel $(0.45 \% \mathrm{C}$ in weight) target, $\mathrm{Fe}$ and $\mathrm{Cu}$ can form chemical compound, indicating that $\mathrm{W}-\mathrm{Cu}$ jet may has an obvious interaction with carbon steel target. For Ti-6Al-4V alloy target, titanium is highly reactive and can easily form chemical compound with both $\mathrm{W}$ and $\mathrm{Cu}$. Thus, the interaction between $\mathrm{W}-\mathrm{Cu}$ jet and Ti-6Al-4V alloy target may be the severest. The mechanical properties, penetration performance and penetration mechanisms of the three targets are studied. The effect of interaction between jet and target on penetration performance is discussed.

\section{Experimental}


The chemical composition (in wt $\%$ ) of the $\mathrm{W}-\mathrm{Cu}$ shaped charge liner material in this study was $80 \mathrm{~W}-20 \mathrm{Cu}$, and the $80 \mathrm{~W}-20 \mathrm{Cu}$ alloy was produced by infiltration. W powder first pressed into a compact $\mathrm{W}$ skeleton, and then the compact $\mathrm{W}$ skeleton was infiltrated by $\mathrm{Cu}$ under the capillary force in a hydrogen atmosphere. The infiltration temperature was $1400^{\circ} \mathrm{C}$, and the holding time was $3 \mathrm{~h}$.

The microstructures of $\mathrm{W}-\mathrm{Cu}$ shaped charge liner materials and the three target materials were observed by OM and SEM. In order to obtain the dynamic yield strength of the three target materials, dynamic compression tests of three target materials were performed by Split Hopkinson Pressure Bar (SHPB) at the strain rate of $3 \times 10^{3} \mathrm{~s}^{-1}$. Then static explosive tests were performed and the three materials were applied as targets. The experimental conditions of static explosive tests remained the same, including the shape of $\mathrm{W}-\mathrm{Cu}$ liners, the quantities of explosive charge and the standoffs.

After the static explosive tests, these targets were retrieved and cleaned, and then cut along the penetration direction by electrical discharge machining. All the sectioned surfaces were polished and etched. In order to reveal the penetration mechanism, scanning electron microscopy (SEM) was employed to observe the microstructural features of penetrated targets. Energy dispersed spectroscopy (EDS) was used to determine the element composition of the penetrated targets. X-ray diffraction (XRD) was performed on the ballistic surfaces of these targets to analyze phase transformation.

\section{Results and Discussion}


Fig. 1 shows the microstructure of the original $80 \mathrm{~W}-20 \mathrm{Cu}$ alloy. The grey part is the $\mathrm{W}$ skeleton composed of $\mathrm{W}$ particles, and the black part is $\mathrm{Cu}$, which fills in the interstices of the W skeleton. The microstructure of the $80 \mathrm{~W}-20 \mathrm{Cu}$ alloy is found to be homogeneous, and the average size of the $\mathrm{W}$ particles is approximately $8 \mu \mathrm{m}$.

Fig. 2 shows the OM images of original microstructures of the Ti-6Al-4V alloy, pure $\mathrm{Cu}$ and carbon steel. It can be observed that the microstructures of Ti-6Al-4V alloy are equiaxed. Pure $\mathrm{Cu}$ has polycrystalline microstructures. Carbon steel has annealed microstructures, consisting of $\alpha-F e$ and pearlite. Microstructures of the three materials are uniform and no obvious microscopic defects are observed.

Fig. 3 shows the true stress-strain curves of the three target materials. It can be found that the dynamic yield strength of Ti-6Al-4V alloy, pure $\mathrm{Cu}$ and carbon steel are $1460 \mathrm{MPa}, 220 \mathrm{MPa}$ and $940 \mathrm{MPa}$, respectively. Then, theoretical penetration ratio of the three target materials is estimated according to Pack's equation. In the equation, since the microstructures of the three materials are nearly full dense, the theoretical densities could be used in calculation. In our previous work, the properties of $\mathrm{W}-\mathrm{Cu}$ jet were systematically investigated [14]. The length of $\mathrm{W}-\mathrm{Cu}$ jet was $158 \mathrm{~mm}$, and the density of $\mathrm{W}-\mathrm{Cu}$ jet was $15.4 \mathrm{~g} / \mathrm{cm}^{3}$. The tip velocity of $\mathrm{W}-\mathrm{Cu}$ jet reached $7300 \mathrm{~m} / \mathrm{s}$. The densities of Ti-6Al-4V alloy, pure $\mathrm{Cu}$ and carbon steel were $4.5 \mathrm{~g} / \mathrm{cm}^{3}, 8.9 \mathrm{~g} / \mathrm{cm}^{3}$ and $7.8 \mathrm{~g} / \mathrm{cm}^{3}$, respectively. According to Pack's empirical equation, the theoretical penetration depth ratio of Ti-6Al-4V alloy, pure $\mathrm{Cu}$ and carbon steel is 10:2.8:5.7.

Table 1 gives the practically relative penetration depth of the three targets against W-Cu jet. Relative penetration depth is the ratio of penetration depth to the diameter 
of liner. In can be seen that the relative penetration depths of Ti-6Al-4V alloy target, carbon steel target and pure $\mathrm{Cu}$ target are 3.5, 7.2 and 9.8, indicating the pure $\mathrm{Cu}$ target has the largest penetration depth. Accordingly, the practical penetration depth ratio of Ti-6Al-4V alloy, pure $\mathrm{Cu}$ and carbon steel is $10: 28: 21$. There is an obvious difference between the theoretical penetration depth and practical penetration depth, indicating that penetration depth is not only affected by the density and strength of the targets. The interaction between jet and target is an important influencing factor.

The extent of curve and roughness of ballistics could reflect the interaction between jet and target. Curving and rough ballistics indicates the interaction is severe between jet and target, while straight and smooth ballistics indicates that jet has a light interaction with target. Fig. 4(a)-(c) show the macro images of ballistic surfaces of Ti-6Al-4V alloy target, pure $\mathrm{Cu}$ target and carbon steel target. It can be seen that the ballistic surfaces show distinctive features. The Ti-6Al-4V alloy target has a curving ballistics and a rough surface, while the carbon steel target has a straight ballistics and still a rough surface. By contrast, the ballistics of pure $\mathrm{Cu}$ target is quite straight and the surface is smooth, indicating that the interaction between $\mathrm{W}-\mathrm{Cu}$ jet and $\mathrm{Cu}$ target may be the lightest.

During the penetration process, jet will have continuous interaction with target. When the velocity of jet slows down to a certain extent, jet stops penetrating and has a severe interaction with the target, which usually results in a coarse ballistic surface [17]. A jet-residual zone is formed on the ballistic surface. The target near the residual jet will be affected by jet and form an affected zone. Some microstructures within the 
affected zone are refined, while others are just deformed [1]. Fig. 5 shows the microstructures of penetrated $\mathrm{Cu}$ target. It can be clearly observed that the width of affected zone is a $0.6 \mathrm{~mm}$. Within the affected zone, $\mathrm{Cu}$ grains are refined due to dynamic recrystallization. A jet-residual zone is also observed on the surface of the ballistics, as shown in Fig. 5(b). At the boundary of the jet-residual zone and the affected zone, a Cu-rich zone is observed, which is marked by the red rectangle. The existing of $\mathrm{Cu}$-rich zone indicates that during the penetration process, $\mathrm{Cu}$ phase in $\mathrm{W}-\mathrm{Cu}$ jet is squeezed out and forms a Cu-rich layer to isolate $\mathrm{W}$ phase and target. $\mathrm{Cu}$-rich layer plays a role in lubricating the ballistics, which explains that the $\mathrm{Cu}$ target has the largest penetration depth.

Fig. 6 shows the microstructures of penetrated carbon steel target. It is found that the width of affected zone in carbon steel target is only $0.4 \mathrm{~mm}$. Within the affected zone, microstructures of carbon steel have severe deformation. However, no obvious grain refinement is observed, illustrating that the interaction between jet and carbon steel target is limited, which is in great agreement with our previous work. Our previous paper [17] proved that the interaction between $\mathrm{Cu}$ and $\mathrm{Fe}$ are not intense, and no ultrahard phases are observed in carbon steel target penetrated by $\mathrm{W}-\mathrm{Cu}$ jet.

The melting point of carbon steel is higher than that of pure $\mathrm{Cu}$, thus the dynamic recrystallization temperature of carbon steel is higher than that of pure $\mathrm{Cu}$. That means $\mathrm{Cu}$ grains are more easily to be refined. Although interaction between the jet and $\mathrm{Cu}$ target is lighter than that between jet and carbon steel target, the width of affected zone in $\mathrm{Cu}$ target is still larger than that of carbon steel. 
Fig. 7 shows the microstructures of penetrated Ti-6Al-4V alloy target. Fig. 7(b), (c) and (d) are the magnification of area B, area C and area D, respectively. Fig. 7(d) shows the original microstructures of Ti-6Al-4V alloy. It can be observed that after penetration, the width of affected zone in Ti-6Al-4V alloy target is at more than $2 \mathrm{~mm}$. Ti-6Al-4V alloy and carbon steel have similar dynamic recrystallization temperature, while the width of the affected zone in Ti-6Al-4V alloy target is 5 times than that of carbon steel target, indicating that the interaction is much more severe between jet and Ti-6Al-4V alloy target. Within the affected zone of Ti-6Al-4V alloy target, a large amount of newly-formed lamellar $\alpha$ phases are observed. The amount of lamellar $\alpha$ phase decreases with the increased distance from the ballistic surface, and the lamellar $\alpha$ phase nearest to ballistic surface is bending. Gao lingli's work [23] proved that original bimodal microstructure of hot-rolled Ti-6Al-4V alloy could transform into the typical lamellar microstructure within several minutes by electric pulse heat treatment. While during the jet penetration process, the interaction between jet and Ti-6Al-4V alloy target is severe, which leads to a high adiabatic temperature and ultra-high pressure. Thus it is reasonable to speculate that there is a phase transformation under the condition of high temperature and ultra-high pressure within a very short time. As the penetration continues, lamellar $\alpha$ phase also has a further deformation. Both phase transformation and deformation of microstructures in Ti-6Al-4V alloy consume a large amount of energy. Thus transverse energy dissipation is huge, which decreases the penetration depth.

In order to identify the interaction between jet and Ti-6Al-4V alloy target, the 
jet-residual zone of Ti-6Al-4V alloy target is further investigated. Fig. 8 shows the microstructures of jet-residual zone in penetrated Ti-6Al-4V alloy target. It can be seen from Fig. 8(b) and (c) that a number of micro shrinkage cavities exist in the jet-residual zone. These micro shrinkage cavities can be considered as evidence of melting, indicating that the Ti-6Al-4V alloy target is melted during the penetration process. The melting of target will increase the interaction between jet and target. Table 2 shows the element composition of different areas, which are marked in Fig. 8. It can be found that $\mathrm{Ti}$ and $\mathrm{Al}$ are existed in the jet-residual zone, proving that the target materials indeed melt and have a severe interaction with $\mathrm{W}-\mathrm{Cu}$ jet during the penetration process.

To verify whether the phase transformation occurs in penetrated target, X-ray diffraction is performed on ballistics surfaces of the three targets, and the results are shown in Fig. 9. It can be found that TiW and CuTi are existed on the ballistic surface of Ti-6Al-4V alloy target. Titanium is a reactive element which can easily interact with both $\mathrm{W}$ and $\mathrm{Cu}$, resulting in the formation of TiW and CuTi in penetrated Ti-6Al-4V alloy target. $\mathrm{Fe}_{7} \mathrm{~W}_{6}$ and $\mathrm{FeCu}_{4}$ are found on the ballistic surface of carbon steel target, proving that $\mathrm{Fe}$ also has obvious interaction with $\mathrm{W}-\mathrm{Cu}$ jet. However, no new phases are found on the ballistic surface of pure $\mathrm{Cu}$ target. This is because neither solid solution nor chemical compound could be formed between $\mathrm{W}$ and $\mathrm{Cu}$, thus the interaction between $\mathrm{W}-\mathrm{Cu}$ jet and pure copper target is the lightest.

It can be concluded that the interaction between jet and $\mathrm{Cu}$ target is slight, which results in a high penetration depth of $\mathrm{Cu}$ target. For the carbon steel target, $\mathrm{Fe}_{7} \mathrm{~W}_{6}$ and 
$\mathrm{FeCu}_{4}$ are found on the ballistic surface, while the width of the affected zone is small, indicating $\mathrm{W}-\mathrm{Cu}$ jet and carbon steel target has a limited interaction. For the Ti-6Al-4V alloy target, TiW and CuTi are existed on the ballistic surface, indicating the interaction between $\mathrm{W}-\mathrm{Cu}$ jet and Ti-6Al-4V alloy target is severe. The severe interaction increases transverse energy dissipation and decreases penetration depth.

According to the above analysis, we propose a modified equation of penetration depth:

$$
P=K\left(\rho_{j} / \rho_{t}\right)^{1 / 2} L\left(1-\alpha \sigma_{t} / V^{2} \rho_{j}\right)
$$

Where $K$ represents an empirical parameter related to the extent of interaction between jet and target. $K=1$, for $\mathrm{Cu}$ target, means jet does not react with target. According to our calculation, $K$ only reaches 0.10 for Ti-6Al-4V target, and 0.27 for carbon steel target when the interaction between jet and target is severe.

In summary, the interaction between jet and target has a significant influence on the penetration depth. Microstructures analysis show that severe interaction leads to formation of new phase, increasing the energy dissipation vertical to the penetration direction, which largely decrease penetration depth. By contrast, light interaction between jet and target will decrease the energy dissipation vertical to the penetration direction, which is beneficial for the jet to obtain a high penetration depth.

\section{Conclusions}

(1) Three kinds of target materials, pure copper, carbon steel and Ti-6Al-4V alloy, were used as targets in explosive tests. Results show that the theoretical penetration depth ratio of Ti-6Al-4V alloy, pure $\mathrm{Cu}$ and carbon steel is 10:2.8:5.7, while the 
practical penetration depth ratio is 10:28:21. The distinctive difference between practical data and calculation indicates that penetration depth is not only affected by properties of jet and target, but also the interaction between them.

(2) No new phases are found on the ballistic surface of pure $\mathrm{Cu}$ target, proving that the interaction between jet and $\mathrm{Cu}$ target is light. $\mathrm{A}$ micro $\mathrm{Cu}$-rich zone exists in the penetrated $\mathrm{Cu}$ target. The $\mathrm{Cu}$-rich zone plays a role in isolating $\mathrm{W}$ phase and target, as well as lubricating the ballistics, which is responsible for the largest penetration depth of penetrated $\mathrm{Cu}$ target.

(3) TiW and CuTi exist on the ballistic surface of the Ti-6Al-4V alloy target, and $\mathrm{Fe}_{7} \mathrm{~W}_{6}$ and $\mathrm{FeCu}_{4}$ are found on the ballistic surface of the carbon steel target. The interaction between jet and Ti-6Al-4V alloy target is the severest, which increases the energy dissipation of the jet and decrease the penetration depth.

(4) The traditional equation of the penetration depth is modified and an empirical parameter is added, which is related to the extent of interaction between jet and target. By using the modified equation, a more accurate penetration depth could be predicted considering the interaction between jet and target.

\section{Acknowledgments}

This research is supported by the National Science Foundation of China (No. 51571033). This work was supported in part by the National Science Foundation of China under Grant No.11521062. China National Key Laboratory of Science and Technology on Materials under Shock and Impact is acknowledged. 


\section{References}

[1] M.A. Meyers, Dynamic Behavior of Materials, John Wiley, New York, 1994.

[2] X. Jia, ZX Huang, XD Zu, 65 (2014) 69-78.

[3] S.T. McWilliams, E.L. Baker, et al., International Infantry and Small Arms Report, NJ, 2002.

[4] X. Jia, Z.X. Huang, X.D. Zu, Int J Impact Eng. 37 (2013) 134-144.

[5] C. Voumard, et al., 19th International Symposium of Ballistics 2001, pp. $1478-1485$.

[6] D.C. Pack, W.M. Evans, Proc. Phys. Soc. London Sect. B 64 (1951) 298-303.

[7] G. Kleiser, D. Lambert, Procedia Engineering. 103 (2015) 302-309.

[8] W. William, G. William, Int J Impact Eng. 26 (2001) 823-830.

[9] M.N. Raftenberg, C.D. Krause, Int J Impact Eng. 23(1999) 757-770.

[10] K. Masahide, T. Atsushi, T. Susumu, Int J Impact Eng. 23 (1999) 443-454.

[11] W.A.Gooch, M.S. Burkins, W.P. Walters, Int J Impact Eng. 26 (2001) 243-248.

[12] W. Guo, S.K. Li, F.C. Wang, 60 (2009) 329-332.

[13] H.K.Shih, L.E.Murr, C.S.Niou, Scr. Metall. Mater. 29 (1993) 1291-1296.

[14] W.Q. Guo, J.X. Liu, et al., Mater. Sci. Eng. A 572 (2013) 36-44.

[15] A.G. Hamidi, H. Arabi, S. Rastegari, Int J Refract Met Hard Mater. 29 (2011) $538-541$.

[16] X.R. Zhang, C. Wu, F.L. Huang. Shock Waves 20 (2010) 263-267.

[17] X. Bai, J.X. Liu, et al., Mater. Sci. Eng. A 553 (2012) 142-148.

[18] M.B. Zellner, R. Becker, D.P. Dandekar, Procedia Engineering 103 (2015) 
663-670.

[19] E.L. Baker, A. Daniels, S. DeFisher, Procedia Engineering 103 (2015) 27-34.

[20] O.V. Svirsky, N.P. Kovalev, B.A. Klopov, Int J Impact Eng. 26 (2001) 735-744.

[21] Z.X. Yin, C.M. Ma, S.X. Li, Mater. Sci. Eng. A 379 (2004) 443-447.

[22] Z.Y. Zhao, J.X. Liu, W.Q. Guo, Int J Refract Met Hard Mater. 54 (2016) 54:90-97.

[23] L.L. Gao, J.X. Liu, X.W. Cheng, Mater. Sci. Eng. A 618 (2014) 104-111.

\section{Figure Captions}

Fig.1 (a): Microstructure of $80 \mathrm{~W}-20 \mathrm{Cu}$ alloy; (b) a higher magnification of 80W-20Cu alloy

Fig. 2 OM images of the original microstructures of: (a) Ti-6Al-4V alloy; (b) pure $\mathrm{Cu}$; (c) carbon steel.

Fig. 3 True stress-strain curves of the three kinds of target materials.

Fig. 4 Macro images of ballistic surfaces: (a) Ti-6Al-4V alloy; (b) pure $\mathrm{Cu}$; (c) carbon steel.

Fig. 5 (a) Microstructures of penetrated pure $\mathrm{Cu}$ target; (b) Magnification of rectangle area in Fig. 4 (a). 
Fig. 6 (a) Microstructures of penetrated carbon steel target; (b) Magnification of rectangle area in Fig. 5 (a) .

Fig. 7 (a): Microstructures of penetrated Ti-6Al-4V alloy target; (b) Magnification of area B in Fig. 6(a); (c) Magnification of area C in Fig. 6(a); (d) Magnification of area D in Fig. 6(a); (e) Original microstructures of Ti-6Al-4V alloy.

Fig. 8 (a): Microstructures of residual jet zone in Ti-6Al-4V alloy target; (b) Magnification graphs of microstructures of residual jet zone; (c) Microstructures of boundary between residual jet and Ti-6Al-4V alloy target.

Fig. 9 XRD results of the three kinds of targets after penetration (a): Ti-6Al-4V; (b) pure $\mathrm{Cu}$ target; (c) carbon steel target.

Table 1 Results of static penetration tests

Table 2 EDS results of different residual jet areas in Fig. 7 


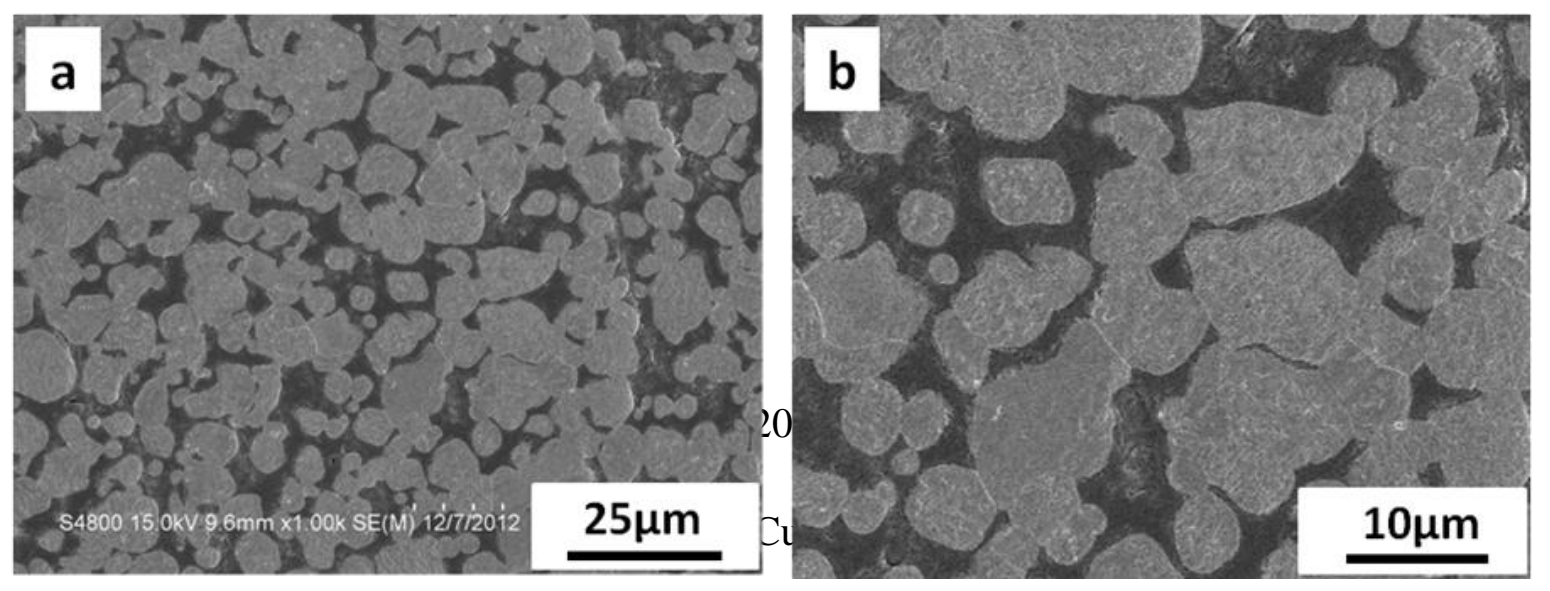




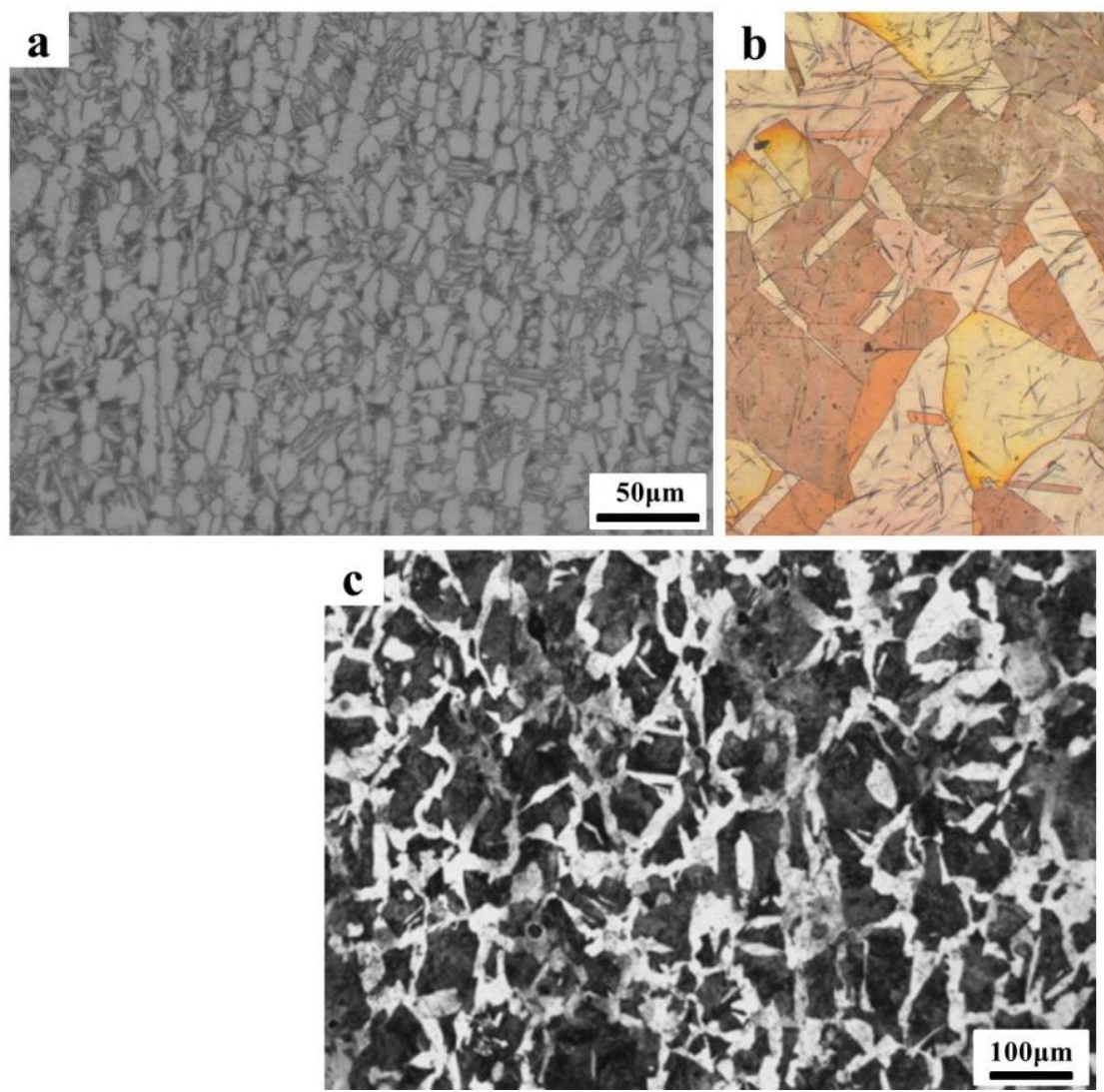

Fig. 2 OM images of the original microstructures of: (a) Ti-6Al-4V alloy; (b) pure $\mathrm{Cu}$; (c) carbon steel. 


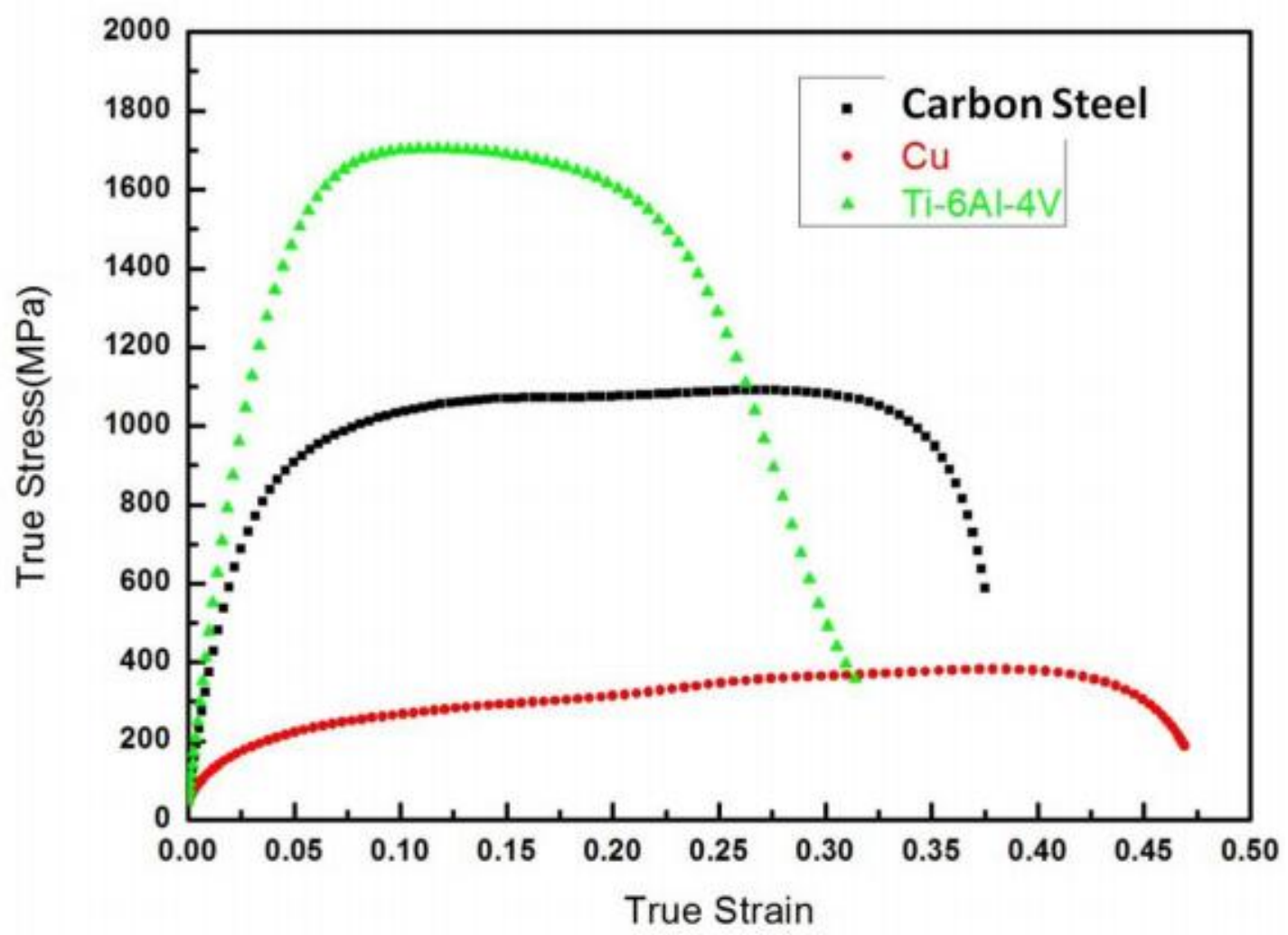

Fig. 3 True stress-strain curves of the three kinds of target materials. 

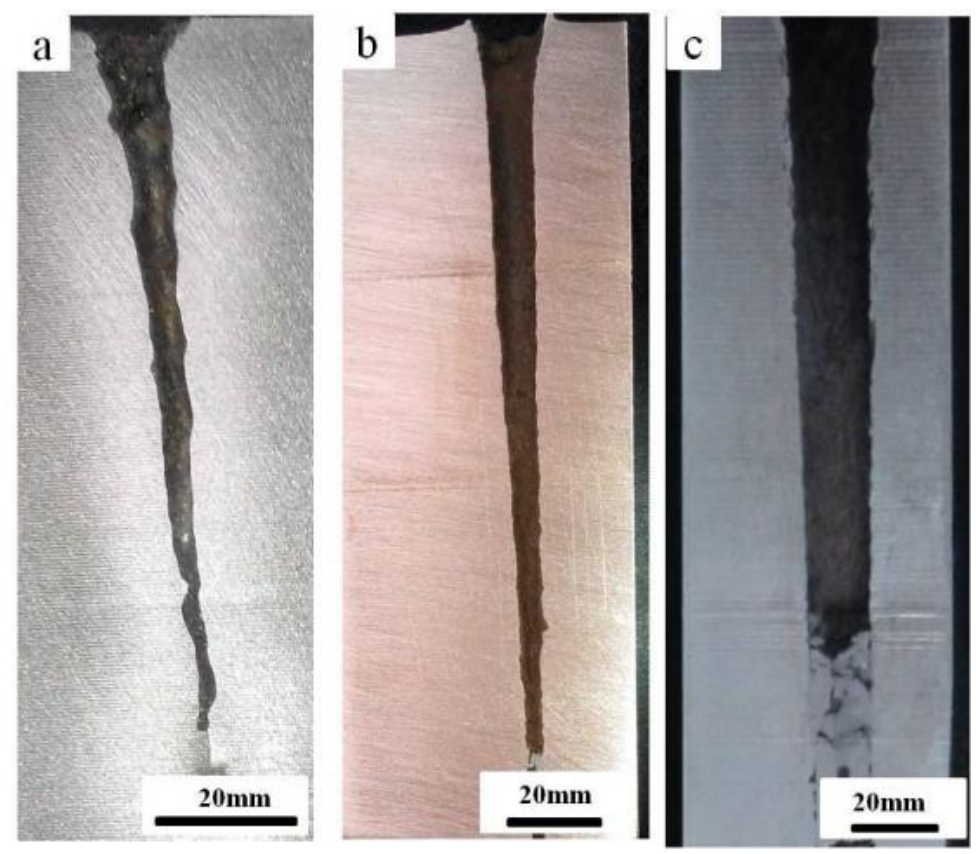

Fig. 4 Macro images of ballistic surfaces: (a) Ti-6Al-4V alloy; (b) pure $\mathrm{Cu}$; (c) carbon steel. 


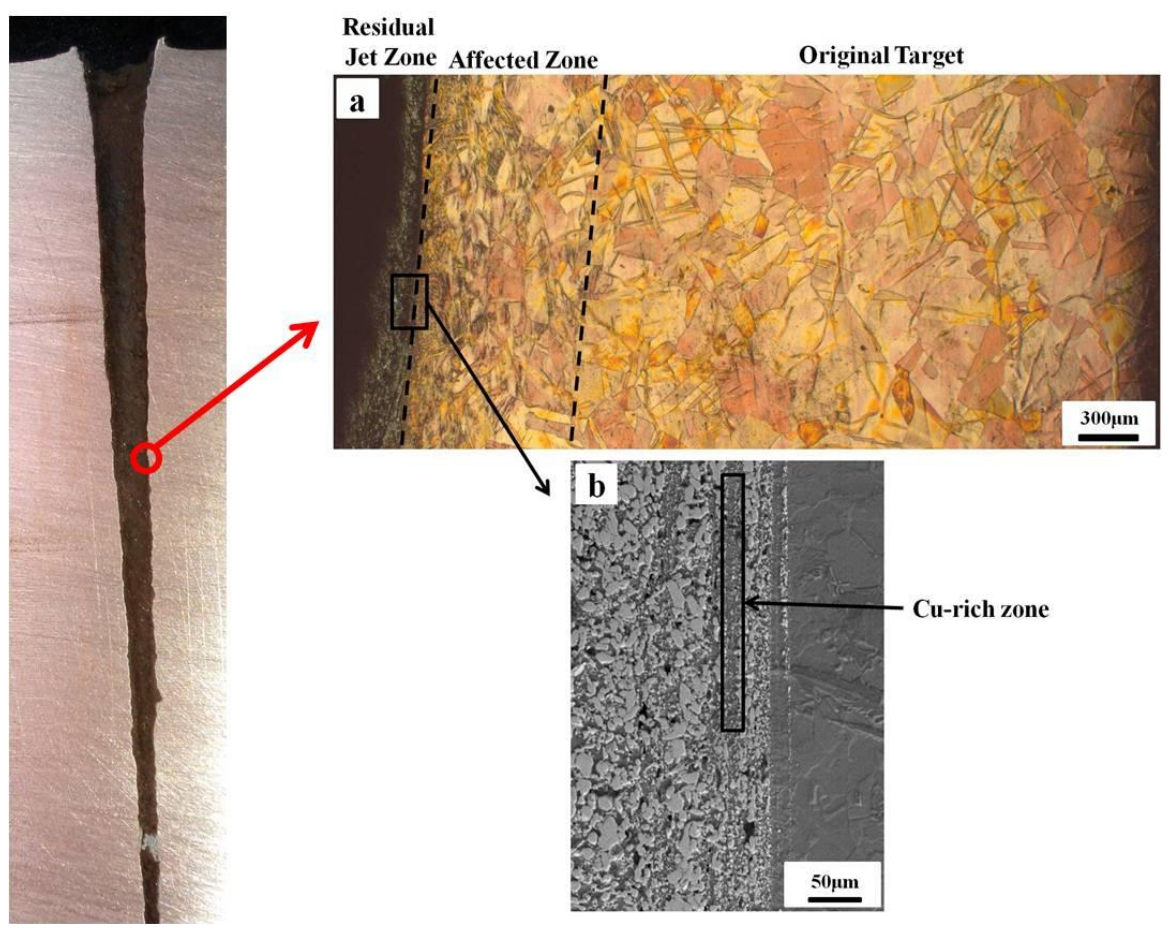

Fig. 5 (a) Microstructures of penetrated pure $\mathrm{Cu}$ target; (b) Magnification of rectangle area in Fig. 4 (a). 


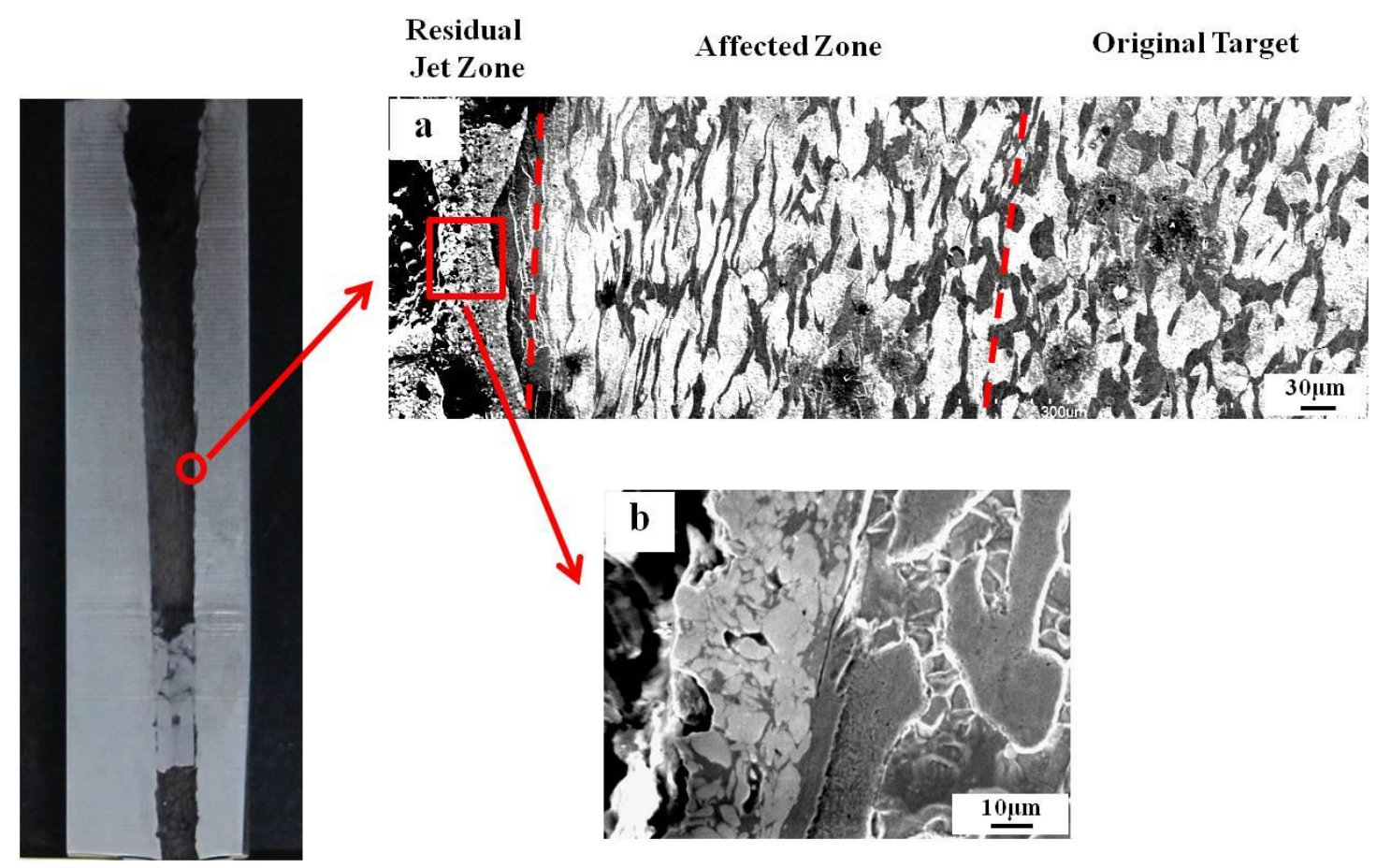

Fig. 6 (a) Microstructures of penetrated carbon steel target; (b) Magnification

of rectangle area in Fig. 5 (a) . 


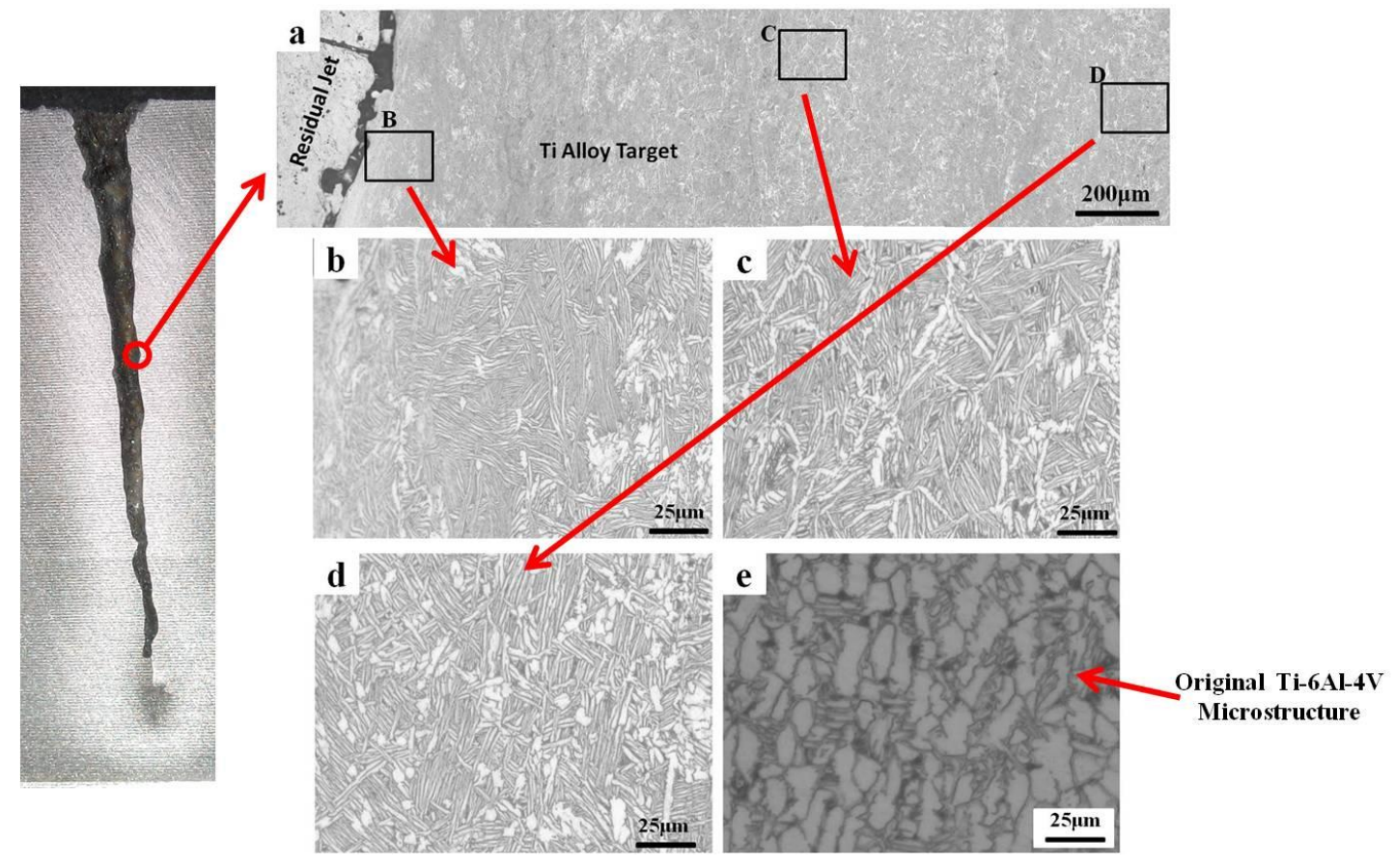

Fig. 7 (a): Microstructures of penetrated Ti-6Al-4V alloy target; (b)

Magnification of area B in Fig. 6(a); (c) Magnification of area C in Fig. 6(a); (d)

Magnification of area D in Fig. 6(a); (e) Original microstructures of Ti-6Al-4V alloy. 

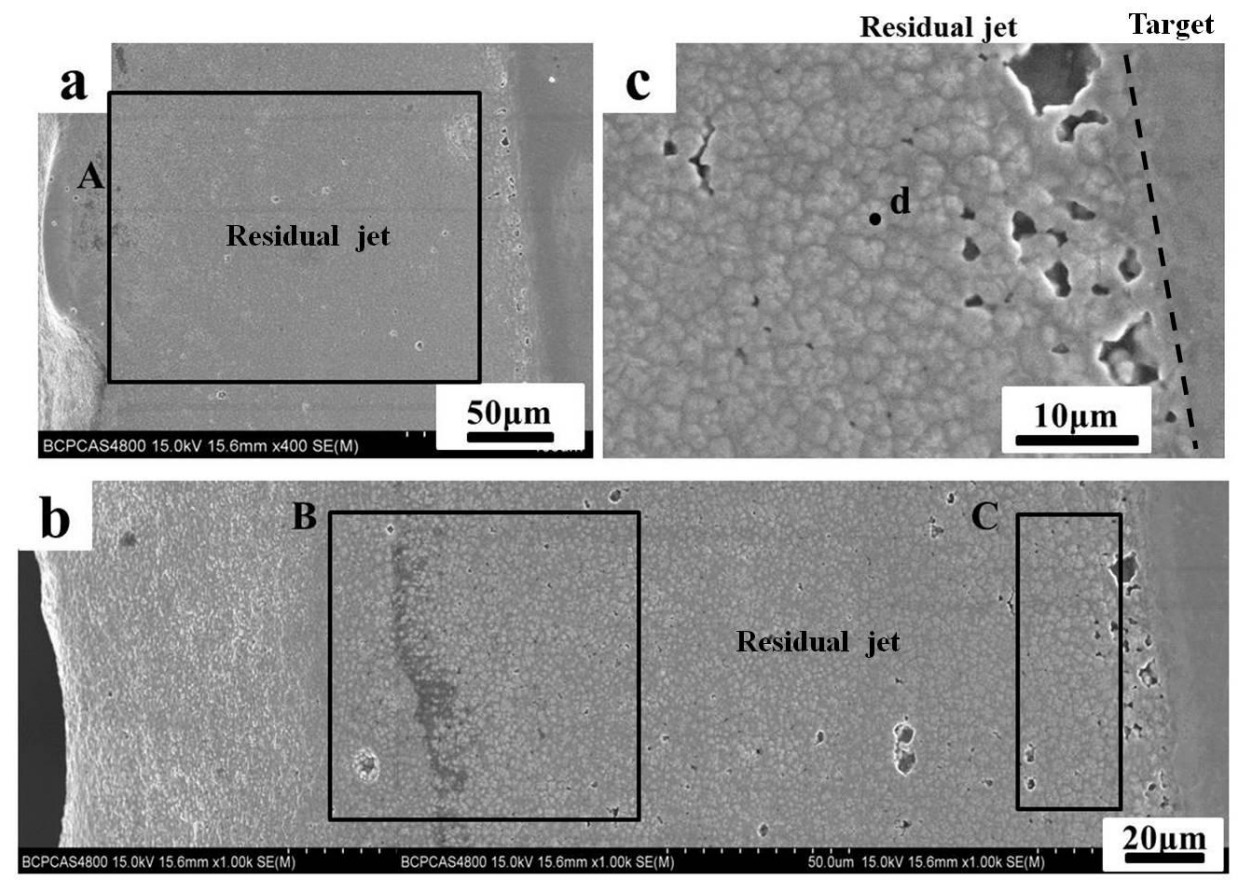

Fig. 8 (a): Microstructures of residual jet zone in Ti-6Al-4V alloy target; (b) Magnification graphs of microstructures of residual jet zone; (c) Microstructures of boundary between residual jet and Ti-6Al-4V alloy target. 


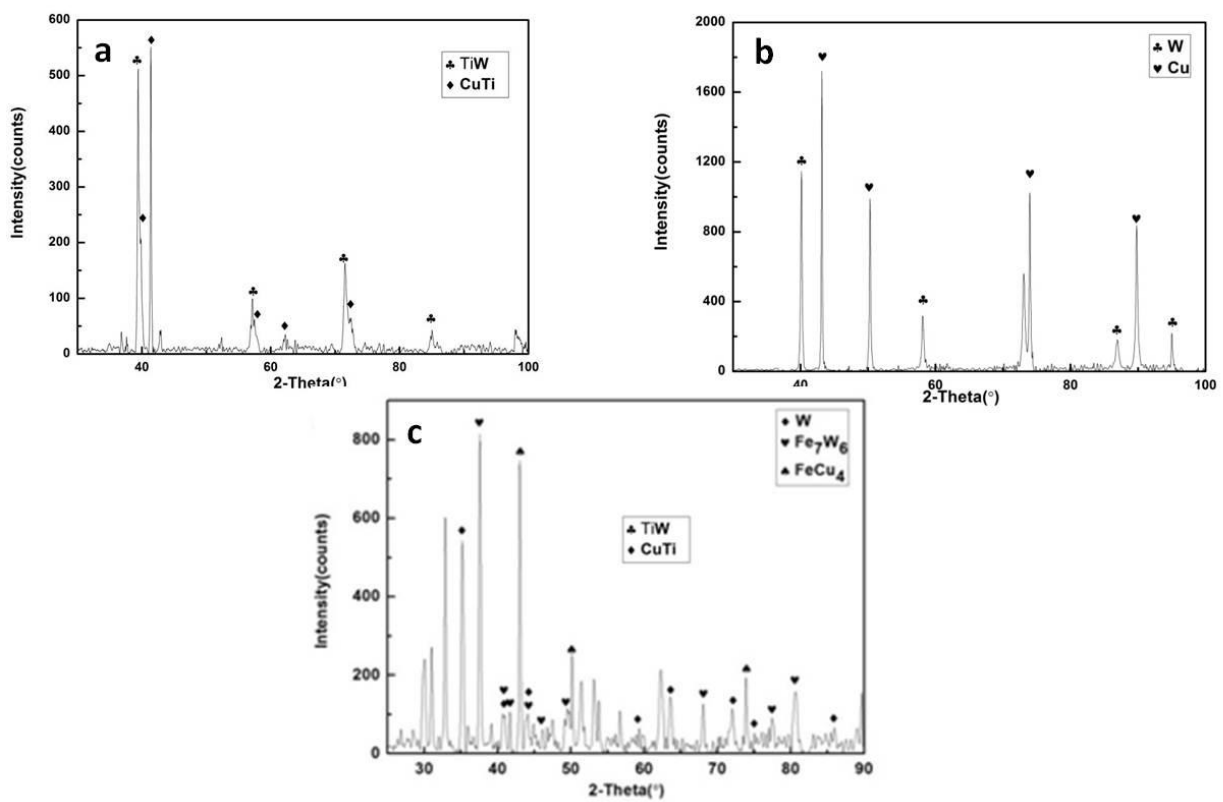

Fig. 9 XRD results of the three kinds of targets after penetration (a):

Ti-6Al-4V; (b) pure Cu target; (c) carbon steel target. 
Table 1 Results of static penetration tests

Target material Relative penetration depth

\begin{tabular}{cc}
\hline Ti-6Al-4V alloy & 3.5 \\
Pure $\mathrm{Cu}$ & 9.8 \\
carbon steel & 7.2 \\
\hline
\end{tabular}


Table 2 EDS results of different residual jet areas in Fig. 7

\begin{tabular}{ccccc}
\hline Element Composition & Area A & Area B & Area C & Point d \\
\hline $\mathrm{Ti}$ & 55.37 & 54.42 & 60.05 & 55.36 \\
$\mathrm{Al}$ & 3.49 & 3.43 & 3.98 & 0 \\
$\mathrm{Cu}$ & 9.20 & 8.73 & 10.57 & 0 \\
$\mathrm{~W}$ & 31.94 & 33.42 & 25.40 & 43.64 \\
\hline
\end{tabular}

